\title{
Analysis of Biofilm-Related Genes and Antifungal Susceptibility Pattern of Vaginal Candida albicans and Non-Candida albicans Species
}

\author{
Faezeh Mohammadi $\mathbb{D},{ }^{1}$ Nima Hemmat $\mathbb{D}^{1},{ }^{1}$ Zahra Bajalan $\mathbb{D}^{2}$ and Amir Javadi $\mathbb{D}^{3}$ \\ ${ }^{1}$ Cellular and Molecular Research Center, Research Institute for Prevention of Non-Communicable Disease, Qazvin University of \\ Medical Sciences, Qazvin 34159-14595, Iran \\ ${ }^{2}$ Social Determinants of Health Research Center, Qazvin University of Medical Sciences, Qazvin 34159-14595, Iran \\ ${ }^{3}$ Department of Social Sciences, School of Medicine, Qazvin University of Medical Sciences, Qazvin 34159-14595, Iran
}

Correspondence should be addressed to Faezeh Mohammadi; esf.mohamadi@gmail.com

Received 14 February 2021; Accepted 16 May 2021; Published 29 May 2021

Academic Editor: Stefania Cantore

Copyright (c) 2021 Faezeh Mohammadi et al. This is an open access article distributed under the Creative Commons Attribution License, which permits unrestricted use, distribution, and reproduction in any medium, provided the original work is properly cited.

\begin{abstract}
Background. Vulvovaginal candidiasis caused by Candida species is a prevalent fungal infection among women. It is believed that the pathogenesis of Candida species is linked with the production of biofilm which is considered a virulence factor for this organism. The aim of this study was molecular identification, antifungal susceptibility, biomass quantification of biofilm, and detection of virulence markers of Candida species. Methods. We investigated the molecular identification of 70 vaginal isolates of Candida species, antifungal resistance to amphotericin B, fluconazole, itraconazole, and voriconazole according to CLSI M27A3 and M27-S4, biofilm formation, and frequency analysis of biofilm-related ALS1, ALS3, and HWP1 genes. Results. Our findings showed that the most common yeast isolated from vaginal discharge was C. albicans (67\%), followed by the nonCandida albicans species (33\%). All C. albicans complex isolates were confirmed as C. albicans by HWP-PCR, and all isolates of the C. glabrata complex were revealed to be C. glabrata sensu stricto using the multiplex PCR method. FLC resistance was observed in $23.4 \%$ of C. albicans and $7.7 \%$ of C. glabrata. The resistance rate to ITC was found in $10.6 \%$ of C. albicans. The frequency of ALS1, ALS3, and HWP1 genes among Candida species was $67.1 \%, 80 \%$, and $81.4 \%$, respectively. Biofilm formation was observed in $54.3 \%$ of Candida species, and the highest frequency detected as a virulence factor was for the ALS3 gene (97.3\%) in biofilm-forming species. Discussion. Our results showed the importance of molecular epidemiology studies, investigating antifungal susceptibility profiles, and understanding the role of biofilm-related virulence markers in the pathogenesis of Candida strains.
\end{abstract}

\section{Introduction}

Vulvovaginal candidiasis (VVC) is a common fungal infection in young women, and several factors such as age, diabetes, pregnancy, taking estrogen-containing birth control pills, antibacterial therapy, and the use of intrauterine devices have been identified as risk factors [1]. Vaginal candidiasis is associated with discharge, inflammation, burning, and redness. Candida albicans is the most important causative agent of VVC, followed by non-Candida albicans species [2]. The diagnosis of vulvovaginal candidiasis is often based on clini- cal signs and symptoms, and fluconazole is mostly used to treat Candida vaginitis. However, variable levels of resistance against antifungals may emerge in Candida species due to empirical administration or overuse of antimycotic agents $[3,4]$. In recent decades, drug resistance has been increasing due to the overuse of antifungals $[5,6]$. Therefore, understanding the antifungal susceptibility profiles of Candida species is key in guiding the selection of appropriate treatment for vulvovaginal candidiasis [6]. On the other hand, the pathogenicity of Candida species is increased with factors such as the ability to produce hyphae, binding and adhesion, 
extracellular enzyme production, and biofilm formation [7, 8]. The agglutinin-like sequence (ALS) gene family is the largest gene family known in C. albicans and is considered one of the important factors in the adhesion of the organism and the formation of biofilm [9]. The ALS gene family consists of several genes including the ALS1-ALS7 and ALS9 genes which play a role in the production of cell surface glycoproteins, leading to increased adhesion to host cells [10]. ALS1 and ALS3 genes affect adhesion to host epithelial cells and endothelial cells $[11,12]$. Another protein affecting the adhesion and regulation of biofilm in C. albicans is the hyphal wall protein produced by the HWP1 gene [13].

HWP1 protein is a mannoprotein-linked glycosyl phosphatidylinositol that, similar to the protein encoded by the ALS family of genes, plays an important role in Candida adhesion [14].

Therefore, this protein is believed to have a significant link with the pathogenicity and virulence of $C$. albicans [14]. Several studies have shown that the HWP1-producing gene is expressed in the early stages of biofilm formation $[15,16]$. The objective of this study was molecular identification, antifungal susceptibility profiling, biomass quantification of biofilm, and analysis of the distribution pattern of ALS1, ALS3, and HWP1 virulence genes of Candida isolates from VVC.

\section{Materials and Methods}

2.1. Sample Collection. A total of 135 genital clinical samples of the married women suspected of VVC were obtained from April to October 2020 who referred to the Kowsar gynecology clinic in Qazvin, Iran. The consent form was obtained from all participants. Pregnancy, douching history of less than past 48 hours, lack of patient contentment, and history of recent consumption of antimicrobials were considered exclusion criteria. The study was approved by the Ethics Committee of Qazvin University of Medical Sciences (IR.QUMS.REC.1397.085). A midwife was in charge of taking the vaginal specimens using sterile swabs, followed by rapid delivery of samples to the Qazvin Medical School mycology laboratory. The Sabouraud dextrose agar medium (SDA, Difco) was used to culture the vaginal sample which was later incubated at $30^{\circ} \mathrm{C}$. The phenotypic test was performed using the chromogenic medium of CHROMagar Candida (CHROMagar Company, Paris, France).

2.2. DNA Extraction and ITS-PCR. Genomic DNA was extracted using glass beads and phenol: chloroform : isoamyl alcohol (25:24:1) [17]. Briefly, the ITS1-5.8S-ITS2 region of Candida species was amplified using universal fungal primers ITS1 (forward $5^{\prime}$-TCCTCCGCTTATTGATAT GC- $3^{\prime}$ ) and ITS4 (reverse $5^{\prime}$-TCCTCCGCTTATTGATAT GC- $3^{\prime}$ ) [15]. The PCR mixture contained $12.5 \mu \mathrm{L}$ of Taq Mix Red 2X, 30 pmol of each primer, and $3 \mu \mathrm{L}$ of the DNA sample in a final volume of $25 \mu \mathrm{L}$. Amplification was performed as follows: initial denaturation at $94^{\circ} \mathrm{C}$ for $5 \mathrm{~min}$, followed by 35 cycles of $30 \mathrm{~s}$ at $94^{\circ} \mathrm{C}, 45 \mathrm{~s}$ at $55^{\circ} \mathrm{C}, 1 \mathrm{~min}$ at $72^{\circ} \mathrm{C}$, and a final extension of $7 \mathrm{~min}$ at $72^{\circ} \mathrm{C}$. The PCR products were analyzed by agarose gel electrophoresis.
2.3. PCR-RFLP Analysis. PCR products were digested with the MspI enzyme (Thermo Fisher Scientific, Lithuania). The $30 \mu \mathrm{L}$ reaction mixture contained $1 \mu \mathrm{L}$ of the $M s p I$ enzyme, $2 \mu \mathrm{L}$ of the buffer, $10 \mu \mathrm{L}$ of the PCR product, and sterile distilled water to the final volume, followed by incubation at $37^{\circ} \mathrm{C}$ for $3 \mathrm{~h}$. The PCR-RFLP products were analyzed by agarose gel electrophoresis.

2.4. Hyphal Wall Protein 1 (HWP1) Gene and Multiplex Polymerase Chain Reaction. All C. albicans isolates were confirmed by PCR amplification of the HWP1 gene, using CR-f and CR-r primer pairs (Table 1). Conditions for HWP-PCR were as follows: initial denaturation at $95^{\circ} \mathrm{C}$ for $5 \mathrm{~min}$, followed by 35 cycles of $45 \mathrm{~s}$ at $94^{\circ} \mathrm{C}, 40 \mathrm{~s}$ at $58^{\circ} \mathrm{C}, 55 \mathrm{~s}$ at $72^{\circ} \mathrm{C}$, and a final extension of $10 \mathrm{~min}$ at $72^{\circ} \mathrm{C}$. The identification of the C. glabrata complex including C. glabrata sensu stricto, C. bracarensis, and C. nivariensis was achieved using the universal reverse primer (UNI-5.8S), GLA-f, NIV-f, and BRA-f (Table 1) [16]. In brief, the reaction mixture contained $12.5 \mu \mathrm{L}$ of Taq Mix Red $2 \mathrm{X}, 0.2 \mu \mathrm{M}$ of each of the four primers, and $10 \mathrm{ng}$ of genomic DNA. Multiplex amplification was performed as follows: initial denaturation at $95^{\circ} \mathrm{C}$ for $5 \mathrm{~min}$, followed by 34 cycles of $30 \mathrm{~s}$ at $94^{\circ} \mathrm{C}, 40 \mathrm{~s}$ at $60^{\circ} \mathrm{C}$, $50 \mathrm{~s}$ at $72^{\circ} \mathrm{C}$, and a final extension of $10 \mathrm{~min}$ at $72^{\circ} \mathrm{C}$.

2.5. Antifungal Susceptibility Test. Susceptibility assay was performed in 96-well plates by following the M27-A3 and M27-S4 guidelines of the Clinical and Laboratory Standards Institute [18] for in vitro testing [19, 20].

The stock solutions of amphotericin B (AMB), fluconazole (FLC), itraconazole (ITC), and voriconazole (VRC) (SigmaAldrich Chemical Corporation, St. Louis, MO, USA) were prepared in the RPMI-1640 medium $(\mathrm{pH}=7.0)$. Briefly, $100 \mu \mathrm{L}$ of the RPMI-1640 medium (Sigma, Germany) and serial dilutions from $\mathrm{AMB}$, ITC, and VRC, ranging from 0.032 to $16 \mu \mathrm{g} / \mathrm{mL}$, and from FLC, ranging from 0.06 to $64 \mu \mathrm{g} / \mathrm{mL}$, were poured in each well. The yeast suspension equal to $0.5 \mathrm{McFar}-$ land $\left(1-5 \times 10^{6}\right.$ cells $\left./ \mathrm{mL}\right)$ was prepared of fresh colonies and diluted at $1: 1000$ with RPMI $\left(1-5 \times 10^{3}\right.$ cells $\left./ \mathrm{mL}\right)$. The final suspensions $(100 \mu \mathrm{L})$ were added to each well, except the control negative well. Minimum inhibitory concentration (MIC) was determined after $48 \mathrm{~h}$ of incubation at $35^{\circ} \mathrm{C}$. Candida parapsilosis (ATCC 22019) and Candida krusei (ATCC 6258) were used as quality controls. Antifungal susceptibility testing was performed in duplicate.

2.6. Biofilm Formation. The biofilm production was evaluated using a $1 \%$ crystal violet $(\mathrm{CV})$ solution in vitro. In brief, the yeast cell suspension and Sabouraud dextrose broth (SDB), supplemented with $60 \mathrm{~g}$ of glucose, were inoculated into wells of 96-well microplates [21]. After incubation at $35^{\circ} \mathrm{C}$ for 24 hours, the wells were washed three times with sterile PBS and stained with crystal violet for $15 \mathrm{~min}$. Finally, fixation was performed using ethanol-acetone $(80: 20, v / v)$. The absorbance values were determined using an ELISA reader at $590 \mathrm{~nm}$. Biofilm formation assay was repeated three times for each strain.

2.7. Scanning Electron Microscopy (SEM). The highest levels of biofilm-forming species among the tested ones were 
TABle 1: The primer sequences for identification of the C. albicans complex, C. glabrata complex, and virulence gene markers.

\begin{tabular}{lrr}
\hline Primer name & Sequence $\left(5^{\prime} \longrightarrow 3^{\prime}\right)$ & Species identified and product size $(\mathrm{bp})$ \\
\hline CR-f & GCTACCACTTCAGAATCATCATC & C. albicans: 1000 \\
CR-r & GCACCTTCAGTCGTAGAGACG & C. dubliniensis: 569 \\
UNI-5.8S & africana: 700 \\
GLA-f & CCCAGAGGGCGCAATGTG & C. glabrata: 397 \\
NIV-f & AGGGAGGAGTTTGTATCTTTCAAC & C. nivariensis: 293 \\
BRA-f & GGGACGGTAAGTCTCCCG & C. bracarensis: 233 \\
ALS1 & ACCAGAAGAAACAGCAGGTG & 319 \\
ALS3 & GACTAGTGAACCAACAAATACCAG & 185 \\
HWP1 & CCAAGTGTTCCAACAACTGAA & 503 \\
\hline
\end{tabular}

selected according to the method for SEM image analysis. After incubation at $35^{\circ} \mathrm{C}$ for 24 hours, the planktonic cells were removed and biofilm cells were fixed with glutaraldehyde. After incubation, the biofilms were dehydrated with various dilutions of ethanol $(20 \%, 40 \%, 60 \%, 80 \%$, and $100 \%)$. Finally, a network of dense hyphal and yeast cells of Candida biofilms was examined with scanning electron microscopy (SEM) [22].

2.8. Detection of Virulence Gene Markers. Extracted DNA was used for amplification of HWP1, ALS1, and ALS3 as virulence genes. The primer sequences are revealed in Table 1. The amplification was performed in a $25 \mu \mathrm{L}$ reaction mixture containing Taq Mix Red 2X, $10 \mathrm{mM}$ of each primer, $10 \mathrm{ng}$ of template DNA, and nuclease-free water up to $25 \mu \mathrm{L}$. The PCR reactions were as follows: initial denaturation at $95^{\circ} \mathrm{C}$ for $5 \mathrm{~min}$, followed by 32 cycles of $1 \mathrm{~min}$ at $95^{\circ} \mathrm{C}, 1 \mathrm{~min}$ at $55^{\circ} \mathrm{C}, 1 \mathrm{~min}$ at $72^{\circ} \mathrm{C}$, and a final extension of $10 \mathrm{~min}$ at $72^{\circ} \mathrm{C}$. The products were visualized by gel electrophoresis.

\section{Results}

A total of 135 vaginal clinical samples of married women suspected of VVC were examined. The mean age of the patients was $31 \pm 6.5$ years (range: 19 to 46 years). Direct examination and culture results showed that out of 135 suspected women included in the present study, 70 (51.8\%) were positive for VVC. Among women who suffered from VVC, the frequency of clinical symptoms included white discharge $(83 \%)$, itching $(77 \%)$, inflammation $(60 \%)$, and irritation $(54.3 \%)$, respectively.

3.1. Candida Species Identification. The PCR amplification of the ITS region of all clinical isolates is shown in Figure 1. The MspI-PCR analysis indicated that C. albicans was the most prevalent isolated species $(47,67 \%)$, followed by C. glabrata (13, 18.5\%), C. kefyr (5, 7\%), C. tropicalis (3, 4.2\%), and C. parapsilosis (2, 2.8\%) (Figure 1).
3.2. Candida albicans and C. glabrata Complex Identification. The multiplex PCR for the identification of 13 isolates of the Candida glabrata complex showed that the amplified products were solely a $397 \mathrm{bp}$ sequence comparable with C. glabrata sensu stricto. None of the isolates belonged to C. nivariensis and C. bracarensis (Figure 1). Furthermore, the molecular identification using the HWP1 gene demonstrated that the PCR product of all isolates was a $1000 \mathrm{bp}$ sequence belonging to C. albicans sensu stricto (Figure 1).

3.3. Antifungal Susceptibility Profile of Vaginal Isolates of Candida species. The antifungal susceptibility profile of 47 C. albicans isolates recovered from VVC showed that all isolates were susceptible to AMB and VRC, whereas eleven isolates $(23.4 \%)$ were resistant to FLC (MIC $\geq 64 \mu \mathrm{g} / \mathrm{mL}$ ), and six isolates (12.8\%) were found to be susceptible-dose dependent (SDD). Furthermore, five isolates (10.6\%) demonstrated the highest MIC to ITC (MIC $\geq 1 \mu \mathrm{g} / \mathrm{mL})$. Among non-Candida albicans species, all C. kefyr, C. tropicalis, and C. parapsilosis were susceptible to AMB, FLC, ITC, and VRC, whereas the resistance rate of C. glabrata to FLC was $7.7 \%$. All C. glabrata isolates were susceptible to AMB, ITC, and VRC. The MIC values and geometric means for FLC, ITC, and VRC are shown in Table 2.

3.4. Biofilm Formation of Candida Species. The rate of biofilm production was detected in $54.3 \%$ of vaginal isolates of Candida with a mean Abs of $0.36 \pm 0.31$. The biofilm production at weak $(+)$, moderate $(++)$, and strong $(+++)$ levels was found in $20 \%, 11.4 \%$, and $21.4 \%$ of Candida isolated from VVC, respectively. In addition, biofilm formation was observed in $26.3 \%$ and $13.2 \%$ of FLC- and ITC-resistant isolates, respectively.

3.5. Detection of Virulence Gene Markers. The frequency of ALS1 and HWP1 genes determined by PCR assay was as follows: $C$. albicans ( $n=37 / 47 ; 78.7 \%$ and $42 / 47 ; 89.4 \%), C$. glabrata $(n=7 / 13 ; 53.8 \%$ and $8 / 13 ; 61.5 \%)$, C. kefyr $(n=2 / 5$ ; $40 \%$ and $4 / 5 ; 80 \%)$, and C. tropicalis $(n=1 / 3 ; 33.3 \%$ and 


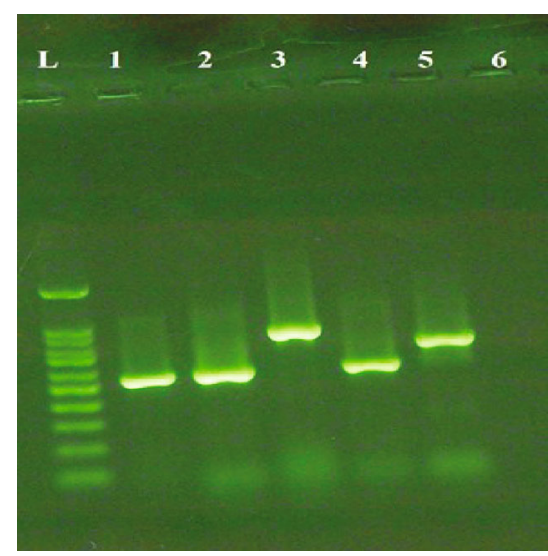

(a)

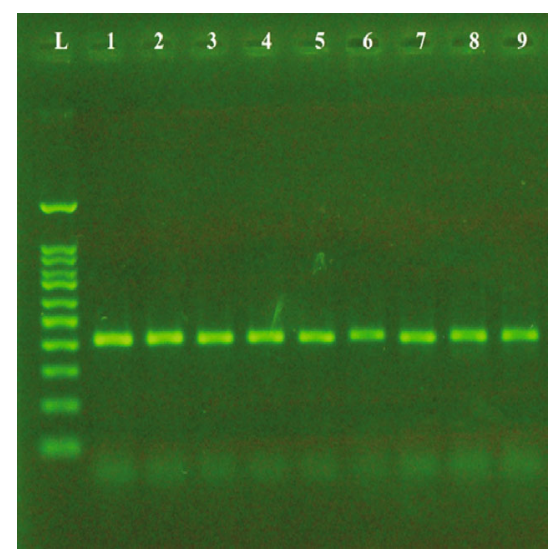

(c)

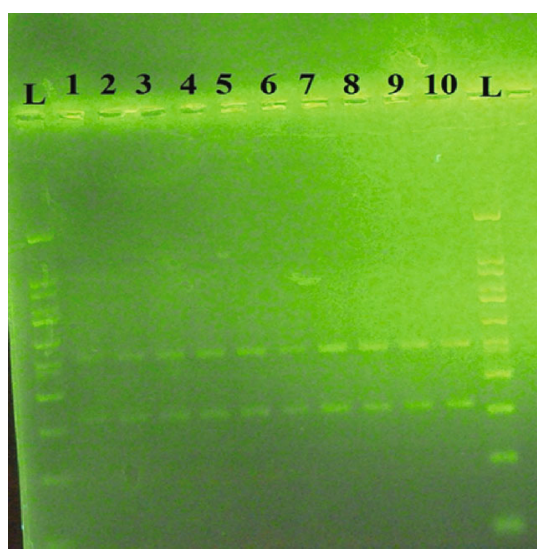

(e)

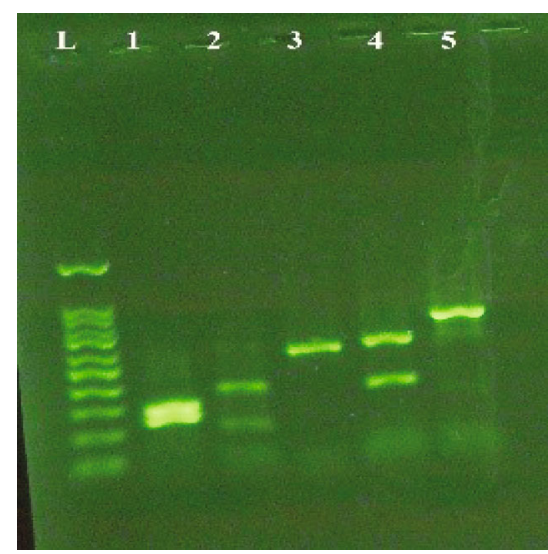

(b)

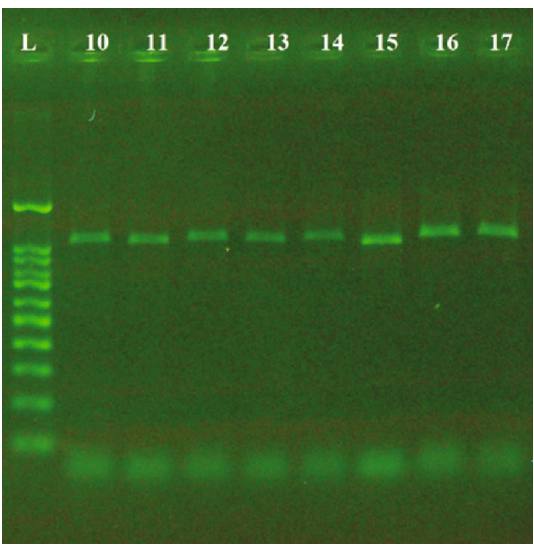

(d)

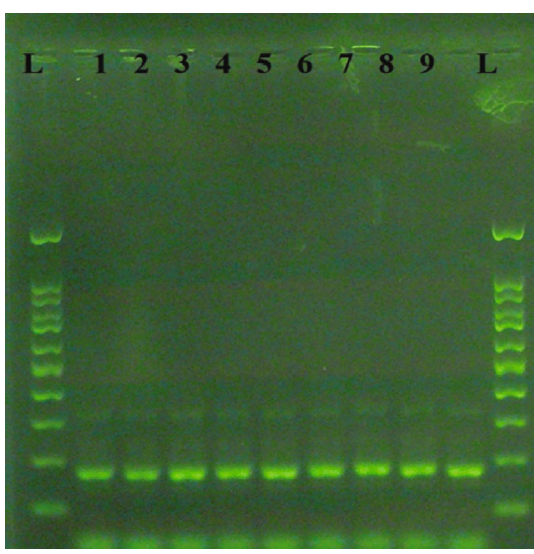

(f)

Figure 1: Lane L: 100 bp DNA size marker. (a) Agarose gel electrophoresis of ITS-PCR products. Lanes 1-5: C. albicans, C. tropicalis, C. glabrata, C. parapsilosis, and C. kefyr. Lane 6: negative control. (b) Agarose gel electrophoresis of MspI-PCR of vaginal Candida species. Lanes 1-5: C. albicans, C. tropicalis, C. parapsilosis, C. glabrata, and C. kefyr. (c) Multiplex PCR method for the C. glabrata complex. Lanes 1-9: C. glabrata. (d) Agarose gel electrophoresis of HWP-PCR. Lanes 10-17: C. albicans. (e) Multiplex PCR products of ALS1 (319 bp) and HWP1 (503 bp) gene strains of Candida species. (f) Agarose gel electrophoresis of PCR for the ALS3 gene (185 bp) of Candida species.

$2 / 3 ; 66.7 \%$ ) (Figure 1). The ALS1 gene was not detected in $C$. parapsilosis, whereas the HWP1 gene was observed in $50 \%$ of C. parapsilosis. The prevalence of the ALS3 gene was in $C$. albicans $(n=43 / 47 ; 91.5 \%)$, C. glabrata $(n=6 / 13 ; 46.2 \%)$, C. kefyr $(n=3 / 5 ; 60 \%)$, C. tropicalis $(n=3 / 3 ; 100 \%)$, and $C$. parapsilosis $(n=1 / 2 ; 50 \%)$ (Figure 1$)$. The simultaneous presence of ALS1, ALS3, and HWP1 genes was observed in $27 \%$ and $15.4 \%$ of fluconazole- and itraconazole-resistant biofilm-producing species, respectively (Table 3 ). The result of SEM of the network of dense hyphal by C. albicans is shown in Figure 2. The simultaneous presence of ALS1, ALS3, and HWP1 genes was found in 95\% of studied strains. 
TABle 2: Antifungal susceptibility pattern of 70 Candida species isolated from vulvovaginal candidiasis.

\begin{tabular}{|c|c|c|c|c|c|}
\hline \multirow[b]{2}{*}{ Species } & \multirow[b]{2}{*}{ Antifungal } & \multirow[b]{2}{*}{ MIC range } & \multicolumn{3}{|c|}{$\operatorname{MICs}^{1}(\mu \mathrm{g} / \mathrm{mL})$} \\
\hline & & & MIC50 & MIC90 & $\mathrm{GM}^{2}$ \\
\hline \multirow{4}{*}{ C. albicans } & $\mathrm{AMB}^{3}$ & $0.032-0.5$ & 0.25 & 0.5 & 0.155 \\
\hline & FLC $^{4}$ & $0.062-64$ & 0.5 & 16 & 1.05 \\
\hline & $\mathrm{ITC}^{5}$ & $0.062-4$ & 0.125 & 0.25 & 0.112 \\
\hline & $\mathrm{VRC}^{6}$ & $0.016-0.125$ & 0.062 & 0.125 & 0.059 \\
\hline \multirow{4}{*}{ C. glabrata } & $\mathrm{AMB}$ & $0.032-0.25$ & 0.125 & 0.25 & 0.091 \\
\hline & FLC & $0.032-64$ & 0.25 & 1 & 0.073 \\
\hline & ITC & $0.016-0.125$ & 0.032 & 0.125 & 0.043 \\
\hline & VRC & $0.032-0.125$ & 0.062 & 0.125 & 0.292 \\
\hline \multirow{4}{*}{ C. kefyr } & $\mathrm{AMB}$ & $0.016-0.032$ & 0.062 & 0.125 & 0.054 \\
\hline & FLC & $0.032-0.25$ & 0.125 & 0.25 & 0.109 \\
\hline & ITC & $0.032-0.125$ & 0.062 & 0.125 & 0.071 \\
\hline & VRC & $0.016-0.125$ & 0.032 & 0.125 & 0.048 \\
\hline \multirow{4}{*}{ C. tropicalis } & $\mathrm{AMB}$ & $0.032-0.016$ & 0.032 & 0.06 & 0.031 \\
\hline & FLC & $0.125-0.5$ & 0.25 & 0.5 & 0.25 \\
\hline & ITC & $0.032-0.125$ & 0.125 & 0.125 & 0.08 \\
\hline & VRC & $0.032-0.016$ & 0.032 & 0.032 & 0.025 \\
\hline \multirow{4}{*}{ C. parapsilosis } & $\mathrm{AMB}$ & $0.032-0.032$ & 0.032 & 0.032 & 0.032 \\
\hline & FLC & $0.5-0.5$ & 0.5 & 0.5 & 0.5 \\
\hline & ITC & $0.032-0.032$ & 0.032 & 0.032 & 0.032 \\
\hline & VRC & $0.016-0.016$ & 0.016 & 0.016 & 0.016 \\
\hline
\end{tabular}

${ }^{1} \mathrm{MIC}$ : minimum inhibitory concentration. ${ }^{2} \mathrm{GM}$ : geometric mean. ${ }^{3} \mathrm{AMB}$ : amphotericin B. ${ }^{4} \mathrm{FLC}$ : fluconazole. ${ }^{5} \mathrm{ITC}$ : itraconazole. ${ }^{6} \mathrm{VRC}$ : voriconazole.

TABle 3: Presence of virulence genes in biofilm-producing Candida species resistant to fluconazole and itraconazole.

\begin{tabular}{lcc}
\hline $\begin{array}{l}\text { Presence of } \\
\text { virulence genes }\end{array}$ & $\begin{array}{c}\text { Biofilm-producing } \\
\text { species and FLC } \\
\text { Resistant }\end{array}$ & $\begin{array}{c}\text { Biofilm-producing } \\
\text { species and ITC } \\
\text { Resistant }\end{array}$ \\
\hline ALS1 & $7(26 \%)$ & $5(18.5 \%)$ \\
ALS3 & $9(25 \%)$ & $5(14 \%)$ \\
HWP1 & $10(29.4 \%)$ & $4(11.8 \%)$ \\
ALS1, ALS3, and & $7(27 \%)$ & $4(15.4 \%)$ \\
HWP1 & & \\
\hline
\end{tabular}

${ }^{1}$ FLC: fluconazole. ${ }^{2}$ ITC: itraconazole.

Comparison of the frequency of virulence genes with the phenotypic biofilm test revealed the presence of ALS1, ALS3, and HWP1 genes in $73 \%, 97.3 \%$, and $89.2 \%$ of biofilm-producing Candida species, respectively.

\section{Discussion}

It is reported that a quarter of women are exposed to vaginal candidiasis during their lifetime [23]. In recent years, there have been reports of non-Candida albicans agents isolated from women with VVC. Our findings showed that the most common yeast isolated from vaginal discharge was C. albicans (67\%), followed by C. glabrata (18.5\%), C. kefyr (7\%), C. tropicalis (4.2\%), and C. parapsilosis (2.8\%) The distribu- tion of Candida isolates in our study was similar to other studies [24-28]. In our study, all the C. albicans complex isolates were confirmed as $C$. albicans based on the presence of a $1000 \mathrm{bp}$ band, whereas no band was detected for either $C$. dubliniensis or C. africana. Shan et al. reported that the $C$. albicans complex isolated from vaginal samples included 98.5\% of C. albicans and 1.5\% of C. africana by HWP-PCR. Meanwhile, the authors failed to demonstrate C. dubliniensis in their samples [29]. Mucci et al. employed CR primers and indicated that the prevalence of C. albicans and C. dubliniensis in the samples obtained from vulvovaginal candidiasis was $94.7 \%$ and $2.6 \%$, respectively [30]. In our study, the multiplex PCR method showed that 13 strains of the vaginal C. glabrata complex were identified as C. glabrata sensu stricto. Li et al. reported that out of $301 \mathrm{C}$. glabrata complex strains isolated from Chinese women with VVC, $97.3 \%, 2.3 \%$, and $0.3 \%$ were identified as C. glabrata, C. nivariensis, and C. bracarensis, respectively [31].

The antifungal susceptibility testing of all Candida isolates in the current study demonstrated that AMB and VRC had excellent antifungal activity against all of the species of Candida evaluated. These findings are in agreement with the data of Montagna et al. from Italy [32], Tseng et al. from Taiwan [33], and Ganeshkumar et al. from India [34]. Lovero et al. showed that Etest is a reliable method for determining the susceptibility of Candida species to L-AMB [35]. In Greece, the antifungal susceptibility profile has shown that Candida isolates from patients with vulvovaginal candidiasis to $\mathrm{AMB}$ and VRC were $0.2 \%$ and $1.4 \%$, respectively [36]. In addition, Ghaddar et al. revealed that $97.5 \%$ of C. albicans isolates from VVC patients were resistant to VRC [37]. Our findings demonstrated that $23.4 \%$ and $10.6 \%$ of C. albicans isolates were resistant to FLC and ITC, respectively. The fluconazole resistance rate was reported from Belgium, Ethiopia, and Taiwan at $21 \%, 53.7 \%$, and $14.7 \%$, respectively [ 25 , $33,38]$. Similarly, Adjapong et al. reported that $10 \%$ of $C$. albicans isolates from VVC patients were resistant to ITC [39]. Edrees et al. showed that $29.6 \%$ of C. albicans isolates from VVC patients were resistant to ITC [40]. In addition, our findings showed that the resistance rate of C. glabrata to fluconazole was $7.7 \%$. Miranda-Cadena et al. showed that the resistance rate to FLC and ITC in C. glabrata was $7.7 \%$ and $6.1 \%$, respectively [41]. In Iowa, $15.2 \%$ of C. glabrata isolates from VVC were fluconazole resistant [42]. Biofilm formation, as a virulence factor, plays an important role in the pathogenesis and binding of Candida species to host cells [43]. In our study, the rate of biofilm production was detected in 54.3\% of VVC-associated Candida species. Biofilm formation was also found in $26.3 \%$ and $13.2 \%$ of FLC- and ITCresistant isolates, respectively. Studies show that Candida species can help to reduce drug penetration and increase antifungal resistance by forming a dense network of pseudohyphae in biofilms [44, 45]. The results of several studies showed that the ALS3 and ALS1 genes of the ALS family as well as the HWP1 gene play an important role in the Candida species adhesion and biofilm formation process [46]. Our results revealed that the highest frequency for the genes tested in the present study was obtained for the HWP1 gene (81.4\%) of Candida species isolated from VVC. ALS3 and 


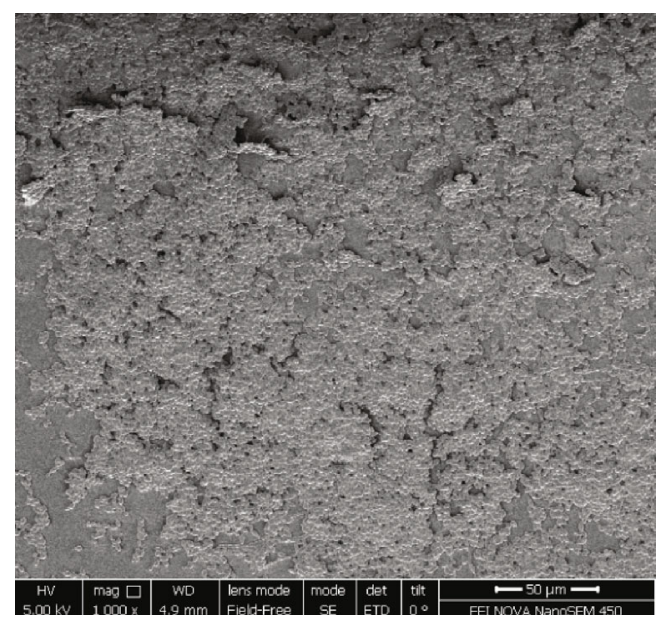

(a)

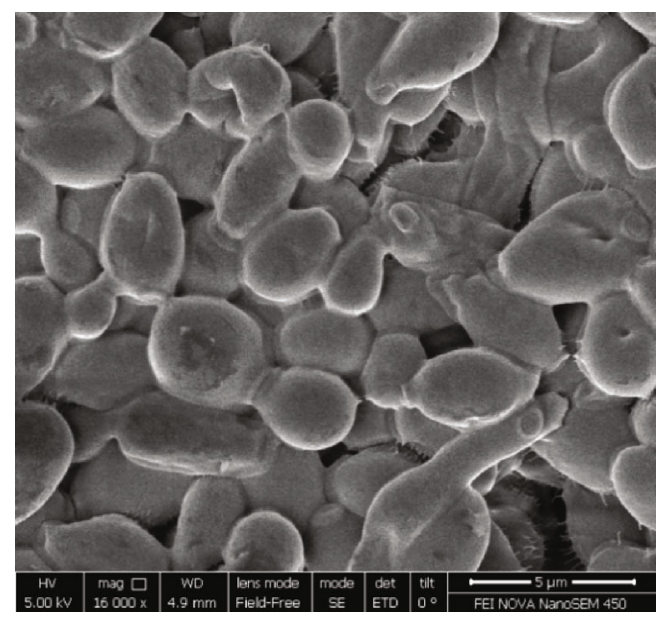

(c)

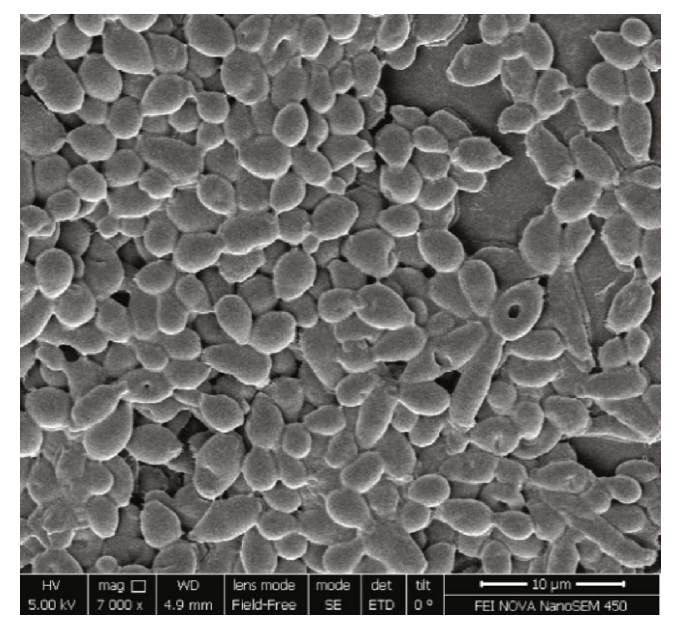

(b)

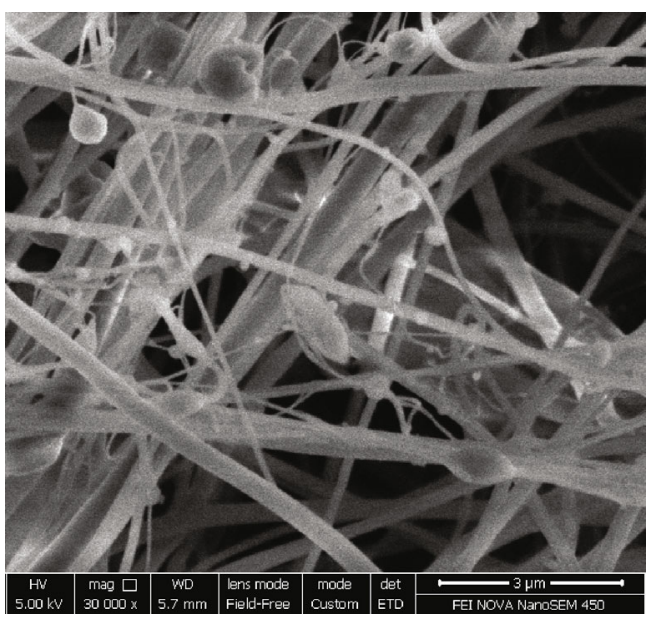

(d)

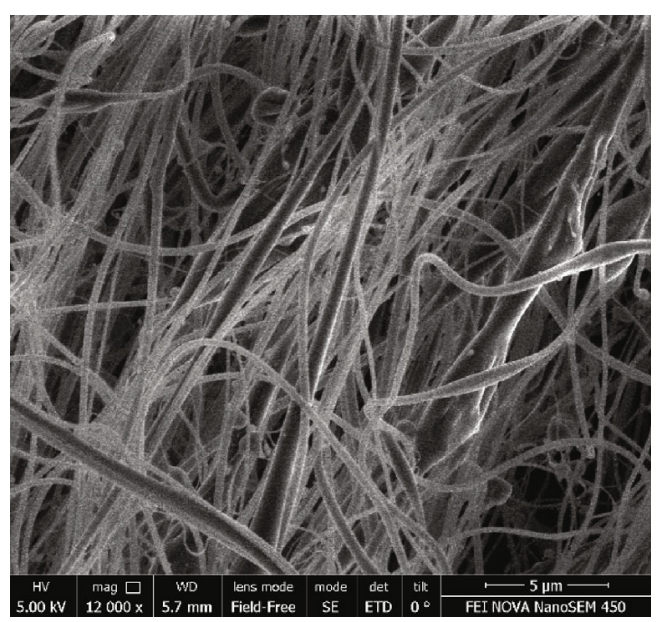

(e)

FIGURE 2: Scanning electron microscopy (SEM) images of the network of dense yeast cells and hyphal in biofilm-forming strains of C. albicans isolated from vaginal samples.

HWP1 genes were detected in all isolates of Candida spp. studied, while the ALS1 gene was not detected in $C$. parapsilosis.

Ardehali et al. reported that the highest virulence factor identified was the HWP1 gene, with a frequency of $95 \%$ in
C. albicans isolated from blood and urinary infections. In their study, the presence of ALS3 and HWP1 genes in C. glabrata was higher than that of the ALS1 gene. In addition, the ALS1 gene was not detected in C. tropicalis [47]. Shrief et al. reported a frequency of $77 \%$ for the HWP1 gene and 
$65 \%$ for the ALS1 gene of C. albicans isolated from blood and urine cultures. They also described that $58 \%$ of C. albicans were capable of biofilm production [48]. The prevalence of the ALS1 and HWP1 genes was detected in $48 \%$ and $3.9 \%$ of the strains isolated from vaginal samples in Turkish women, respectively [49].

A study on Brazilian women showed that the frequency of ALS1 and HWP1 genes in the C. albicans collected from vaginal discharge was $73.6 \%$ and $21 \%$, respectively [50]. Differences in the type of clinical samples and techniques used for diagnosis may cause variations in the frequency of genes in various studies. There are many reports that have been concerned with the expression of ALS and HWP genes. Cheng et al. indicated that the ALS1 and ALS3 genes were expressed in both the clinical vaginal discharge and the experimental model system for vaginal candidiasis [51]. The results of our study and several other studies have shown that the frequency of the presence of these genes and their expression in clinical isolates can indicate the role of these genetic markers in promoting the adhesion and biofilm formation in Candida species, especially $C$. albicans. Moreover, the simultaneous presence of ALS1, ALS3, and HWP1 genes plays a role in enhancing the synergistic effect on the performance of individual genes involved $[13,52]$. In our study, the frequency of the ALS3 gene was found in $94.7 \%$ of biofilm-positive species which was higher than the other genes examined. Furthermore, the simultaneous presence of ALS1, ALS3, and HWP1 genes in biofilm-producing Candida species was $52.8 \%$. In Egypt, the biofilm capacity was observed in $58 \%$ of Candida albicans isolates from the chemotherapy patients. Also, the prevalence of ALS1 and HWP1 genes among the biofilmpositive C. albicans was 56.9\% [48]. Inci et al. showed the presence of ALS1 and HWP1 genes in $83.1 \%$ and $11.3 \%$, respectively, of biofilm-producing isolates [49].

\section{Conclusion}

In our study, C. albicans showed the highest frequency for ALS1, ALS3, and HWP1 genes. This high prevalence rate for virulence factors is significant in C. albicans vaginal specimens. It is of great concern that several studies have shown that Candida biofilm formation may be involved in resistance to antifungals. Since biofilm formation affects the process of vulvovaginal candidiasis infection, it is important to understand the role of virulence factors in the pathogenesis of Candida species.

\section{Data Availability}

The data used to support the findings of this study are available from the corresponding author upon request.

\section{Conflicts of Interest}

The authors reported that they have no conflicts of interest in this paper.

\section{Authors' Contributions}

The contributions of the authors involved in this study are as follows: Faezeh Mohammadi: responsible for design and supervision; Nima Hemmat: collaboration in sampling and practical work; Zahra Bajalan: diagnosis of the disease as a midwife; and Amir Javadi: data analysis. All authors contributed to the writing of the article.

\section{Acknowledgments}

The authors thank all the participants for their cooperation, as well as the Vice-Chancellor for Research and Technology Affairs of Qazvin University of Medical Sciences. This research was financially supported by Qazvin University of Medical Sciences.

\section{References}

[1] L. Mtibaa, N. Fakhfakh, A. Kallel et al., "Les candidoses vulvovaginales : etiologies, symptomes et facteurs de risque," Journal de Mycologie Medicale, vol. 27, no. 2, pp. 153-158, 2017.

[2] O. Makanjuola, F. Bongomin, and S. A. Fayemiwo, "An update on the roles of non-albicans Candida species in vulvovaginitis," Journal of Fungi, vol. 4, no. 4, p. 121, 2018.

[3] S. D. Rathod, J. D. Klausner, K. Krupp, A. L. Reingold, and P. Madhivanan, "Epidemiologic features of vulvovaginal candidiasis among reproductive-age women in India," Infectious Diseases in Obstetrics and Gynecology, vol. 2012, Article ID 859071, 8 pages, 2012.

[4] M. I. Rosa, B. R. Silva, P. S. Pires et al., "Weekly fluconazole therapy for recurrent vulvovaginal candidiasis: a systematic review and meta-analysis," European Journal of Obstetrics, Gynecology, and Reproductive Biology, vol. 167, no. 2, pp. 132-136, 2013.

[5] S. Hilmioğlu-Polat, S. Sharifynia, Y. Öz et al., "Genetic diversity and antifungal susceptibility of Candida parapsilosis sensu stricto isolated from bloodstream infections in Turkish patients," Mycopathologia, vol. 183, no. 4, pp. 701-708, 2018.

[6] J. Rolo, P. Faria-Gonçalves, T. Barata et al., "Species distribution and antifungal susceptibility profiles of isolates from women with nonrecurrent and recurrent vulvovaginal candidiasis," Microbial Drug Resistance, 2021.

[7] F. L. Mayer, D. Wilson, and B. Hube, "Candida albicans pathogenicity mechanisms," Virulence, vol. 4, no. 2, pp. 119-128, 2013.

[8] C. Rodríguez-Cerdeira, M. C. Gregorio, A. Molares-Vila et al., "Biofilms and vulvovaginal candidiasis," Colloids and Surfaces. B, Biointerfaces, vol. 174, pp. 110-125, 2019.

[9] L. L. Hoyer, "The _ALS_ gene family of_Candida albicans_," Trends in Microbiology, vol. 9, no. 4, pp. 176-180, 2001.

[10] L. L. Hoyer and E. Cota, "Candida albicans agglutinin-like sequence (Als) family vignettes: a review of Als protein structure and function," Frontiers in Microbiology, vol. 7, p. 280, 2016.

[11] Q. T. Phan, C. L. Myers, Y. Fu et al., "Als3 is a Candida albicans invasin that binds to cadherins and induces endocytosis by host cells," PLoS Biology, vol. 5, no. 3, article e64, 2007.

[12] H. Nailis, R. Vandenbroucke, K. Tilleman, D. Deforce, H. Nelis, and T. Coenye, "Monitoring ALS1 and ALS3 gene expression during in vitro Candida albicans biofilm formation 
under continuous flow conditions," Mycopathologia, vol. 167, no. 1, pp. 9-17, 2009.

[13] C. J. Nobile, J. E. Nett, D. R. Andes, and A. P. Mitchell, "Function of Candida albicans adhesin Hwp1 in biofilm formation," Eukaryotic Cell, vol. 5, no. 10, pp. 1604-1610, 2006.

[14] J. F. Staab, Y.-S. Bahn, C.-H. Tai, P. F. Cook, and P. Sundstrom, "Expression of transglutaminase substrate activity on _Candida albicans_ germ tubes through a coiled, disulfide-bonded $\mathrm{N}$-terminal domain of Hwp1 requires C-terminal glycosylphosphatidylinositol modification," Journal of Biological Chemistry, vol. 279, no. 39, pp. 40737-40747, 2004.

[15] M. Javaheri, F. Mohammadi, M. Chadeganipour, S. Nekoian, and P. Dehghan, "Identification of Candida species in oral cavity of smokers and nonsmokers," Journal of Isfahan Medical School, vol. 33, no. 362, pp. 2105-2110, 2016.

[16] O. Romeo, F. Scordino, I. Pernice, C. L. Passo, and G. Criseo, "A multiplex PCR protocol for rapid identification of _Candida glabrata_ and its phylogenetically related species _Candida nivariensis_ and _Candida bracarensis_," Journal of Microbiological Methods, vol. 79, no. 1, pp. 117120, 2009.

[17] F. Mohammadi, S. J. Hashemi, S. M. Seyedmousavi, and D. Akbarzade, "Isolation and characterization of clinical triazole resistance Aspergillus fumigatus in Iran," Iranian Journal of Public Health, vol. 47, no. 7, pp. 994-1000, 2018.

[18] CLSI, Reference Method for Broth Dilution Antifungal Susceptibility Testing of Filamentous Fungi. Approved Standard M38-A2, Clinical and Laboratory Standards Institute, Wayne, PA, 2008.

[19] P. Wayne, Clinical and Laboratory Standards Institute (CLSI): Reference Method for Broth Dilution Antifungal Susceptibility Testing of Filamentous Fungi, Allured Publishing Corporation, Carol Stream, IL, 2008.

[20] M. Ghannoum, Reference Method for Broth Dilution Antifungal Susceptibility Test of Yeast M27-s4, CLSI, 2012.

[21] S. Silva, M. Henriques, A. Martins, R. Oliveira, D. Williams, and J. Azeredo, "Biofilms of non-Candida albicans Candida species: quantification, structure and matrix composition," Sabouraudia, vol. 47, no. 7, pp. 681-689, 2009.

[22] F. Mohammadi, Z. Ghasemi, B. Familsatarian et al., "Relationship between antifungal susceptibility profile and virulence factors in Candida albicans isolated from nail specimens," Revista da Sociedade Brasileira de Medicina Tropical, vol. 53, 2020.

[23] R. Jeanmonod and D. Jeanmonod, Vaginal candidiasis, StatPearls, 2020.

[24] D. N. Anh, L. T. Anh, L. B. Quang et al., "Prevalence of Candida species isolated from vaginal discharge of women undergoing in vitro fertilization-embryo transfer in Vietnam," Biomedical Journal of Scientific \& Technical Research, vol. 14, no. 5, pp. 1-4, 2019.

[25] A. Tsega and F. Mekonnen, "Prevalence, risk factors and antifungal susceptibility pattern of Candida species among pregnant women at Debre Markos Referral Hospital, Northwest Ethiopia," BMC Pregnancy and Childbirth, vol. 19, no. 1, pp. 527-528, 2019.

[26] A. Bitew and Y. Abebaw, "Vulvovaginal candidiasis: species distribution of Candida and their antifungal susceptibility pattern," BMC Women's Health, vol. 18, no. 1, p. 94, 2018.

[27] M. A. Hussein, A. S. Yassin, and F. H. El-Gelany, "Characterization, virulence factors and antifungal susceptibility of vul- vovaginal Candida isolated from women at Qena, Egypt," Egyptian Journal of Microbiology, vol. 54, no. 1, pp. 13-24, 2019.

[28] B. Bonyadpour, M. Akbarzdeh, and A. A. Mohagheghzadeh, "Characterization of Candida species isolated from cases of vulvovaginitis in women referring to selected gynecological clinics," Journal of Midwifery and Reproductive Health, vol. 4, no. 4, pp. 741-747, 2016.

[29] Y. Shan, S. Fan, X. Liu, and J. Li, "Prevalence of Candida albicans-closely related yeasts, Candida africana and Candida dubliniensis, in vulvovaginal candidiasis," Medical Mycology, vol. 52, no. 6, pp. 636-640, 2014.

[30] M. J. Mucci, M. L. Cuestas, M. F. Landanburu, and M. T. Mujica, "Prevalencia de_Candida albicans_,_Candida dubliniensis_y_Candida africana_en mujeres gestantes con candidiasis vulvovaginal, en Argentina," Revista Iberoamericana de Micología, vol. 34, no. 2, pp. 72-76, 2017.

[31] J. Li, Y. Shan, S. Fan, and X. Liu, "Prevalence of Candida nivariensis and Candida bracarensis in vulvovaginal candidiasis," Mycopathologia, vol. 178, no. 3-4, pp. 279-283, 2014.

[32] M. T. Montagna, G. Lovero, C. Coretti et al., "In vitro activities of amphotericin B deoxycholate and liposomal amphotericin B against 604 clinical yeast isolates," Journal of Medical Microbiology, vol. 63, no. 12, pp. 1638-1643, 2014.

[33] Y.-H. Tseng, W.-T. Lee, and T.-C. Kuo, "In-vitro susceptibility of fluconazole and amphotericin B against Candida isolates from women with vaginal candidiasis in Taiwan," Journal of Food and Drug Analysis, vol. 13, no. 1, pp. 12-16, 2005.

[34] A. Ganeshkumar, P. Nagarajan, P. Mahalingam et al., "Antifungal susceptibility and virulence profile of Candida isolates from abnormal vaginal discharge of women from southern India," European Journal of Obstetrics, Gynecology, and Reproductive Biology, vol. 254, pp. 153-158, 2020.

[35] G. Lovero, O. De Giglio, S. Rutigliano, G. Diella, G. Caggiano, and M. T. Montagna, "In vitro antifungal susceptibilities of Candida species to liposomal amphotericin B, determined using CLSI broth microdilution, and amphotericin B deoxycholate, measured using the Etest," Journal of Medical Microbiology, vol. 66, no. 2, pp. 213-216, 2017.

[36] S. Maraki, V. E. Mavromanolaki, D. Stafylaki, E. Nioti, G. Hamilos, and A. Kasimati, "Epidemiology and antifungal susceptibility patterns of Candida isolates from Greek women with vulvovaginal candidiasis," Mycoses, vol. 62, no. 8, pp. 692-697, 2019.

[37] N. Ghaddar, E. Anastasiadis, R. Halimeh et al., "Prevalence and antifungal susceptibility of Candida albicans causing vaginal discharge among pregnant women in Lebanon," $B M C$ Infectious Diseases, vol. 20, no. 1, pp. 32-39, 2020.

[38] T. G. Bauters, M. A. Dhont, M. I. Temmerman, and H. J. Nelis, "Prevalence of vulvovaginal candidiasis and susceptibility to fluconazole in women," American Journal of Obstetrics and Gynecology, vol. 187, no. 3, pp. 569-574, 2002.

[39] G. Adjapong, M. Hale, and A. Garrill, "A comparative investigation of azole susceptibility in Candida isolates from vulvovaginal candidiasis and recurrent vulvovaginal candidiasis patients in Ghana," Medical Mycology, vol. 55, no. 6, pp. 686-689, 2016.

[40] W. H. Edrees, A. A. Al-Asbahi, W. A. Al-Shehari, and E. A. Qasem, "Vulvovaginal candidiasis prevalence among pregnant women in different hospitals in Ibb, Yemen," UJPR, vol. 5, no. 4 , pp. $1-5,2020$. 
[41] K. Miranda-Cadena, C. Marcos-Arias, E. Mateo, J. M. Aguirre, G. Quindós, and E. Eraso, "Prevalence and antifungal susceptibility profiles of_Candida glabrata_,_Candida parapsilosis_ and their close-related species in oral candidiasis," Archives of Oral Biology, vol. 95, pp. 100-107, 2018.

[42] S. S. Richter, R. P. Galask, S. A. Messer, R. J. Hollis, D. J. Diekema, and M. A. Pfaller, "Antifungal susceptibilities of Candida species causing vulvovaginitis and epidemiology of recurrent cases," Journal of Clinical Microbiology, vol. 43, no. 5, pp. 2155-2162, 2005.

[43] G. Ramage, K. Vandewalle, B. L. Wickes, and J. L. López-Ribot, "Characteristics of biofilm formation by Candida albicans," Revista Iberoamericana de Micología, vol. 18, no. 4, pp. 163$170,2001$.

[44] M. B. Lohse, M. Gulati, C. S. Craik, A. D. Johnson, and C. J. Nobile, "Combination of antifungal drugs and protease inhibitors prevent Candida albicans biofilm formation and disrupt mature biofilms," Frontiers in Microbiology, vol. 11, p. 1027, 2020.

[45] R. Pereira, R. O. dos Santos Fontenelle, E. H. S. de Brito, and S. M. de Morais, "Biofilm ofCandida albicans: formation, regulation and resistance," Journal of Applied Microbiology, 2020.

[46] M. S. A. Khan, I. Ahmad, F. Aqil, M. Owais, M. Shahid, and J. Musarrat, "Virulence and pathogenicity of fungal pathogens with special reference to Candida albicans," Combating Fungal Infections, pp. 21-45, 2010.

[47] S. H. Ardehali, T. Azimi, F. Fallah et al., "Molecular detection of ALS1, ALS3, HWP1 and SAP4 genes in Candida genus isolated from hospitalized patients in intensive care unit, Tehran, Iran," Cellular and Molecular Biology, vol. 65, no. 4, pp. 15-22, 2019.

[48] R. Shrief, M. E. S. Zaki, E. M. el-Sehsah, S. Ghaleb, and M. Mofreh, "Study of antifungal susceptibility, virulence genes and biofilm formation in Candida albicans," The Open Microbiology Journal, vol. 13, no. 1, pp. 241-248, 2019.

[49] M. Inci, M. A. Atalay, B. Özer et al., "Investigations of ALS1 and HWP1 genes in clinical isolates of Candida albicans," Turkish Journal of Medical Sciences, vol. 43, no. 1, pp. 125130, 2013.

[50] L. S. Goulart, J. S. de Lima, W. W. R. de Souza, C. A. Vieira, J. Crestani, and C. Araújo, "Analysis of the ALS1 and HWP1 genes from clinical isolates of Candida albicans/Análise de genes ALS1 e HWP1 em isolados clínicos de Candida albicans," Brazilian Journal of Health Review, vol. 1, no. 1, pp. 112-119, 2018.

[51] G. Cheng, K. Wozniak, M. A. Wallig, P. L. Fidel, S. R. Trupin, and L. L. Hoyer, "Comparison between Candida albicans agglutinin-like sequence gene expression patterns in human clinical specimens and models of vaginal candidiasis," Infection and Immunity, vol. 73, no. 3, pp. 1656-1663, 2005.

[52] D. R. Soll, “_Candida_biofilms: is adhesion sexy?,” Current Biology, vol. 18, no. 16, pp. R717-R720, 2008. 